\title{
MANAGEMENT OF INTRA-ARTICULAR CALCANEAL FRACTURES WITH REDUCTION AND PERCUTANEOUS FIXATION
}

\author{
Kishan Gopal Nama1, Ram Khiladi Meena², Shiv Bhagwan Sharma ${ }^{3}$
}

${ }_{1}^{1}$ Assistant Professor, Department of Orthopaedics, MBS Hospital and Government Medical College, Kota. ${ }^{2}$ Assistant Professor, Department of Orthopaedics, MBS Hospital and Government Medical College, Kota. ${ }^{3}$ Professor, Department of Orthopaedics, MBS Hospital and Government Medical College, Kota.

\section{ABSTRACT}

\section{BACKGROUND}

Calcaneum, the largest and strongest cancellous tarsal bone is very well designed to bear the body weight. It endures a lot of daily activity stresses. The bone is unique in that it is actually hard on the outside and because of sparse trabeculae, soft on the inside, making it prone to impaction of articular surface, fragmentation and collapse on a high-velocity impact to the heel mostly during fall from height.

The aim of this study is to report techniques and results of percutaneous fixation of intra-articular calcaneal fractures.

\section{MATERIALS AND METHODS}

Between July 2011 to August 2013, 40 intra-articular calcaneal fractures in 36 patients were treated by closed reduction and percutaneous fixation using partially threaded cancellous screws. Postoperatively range of motion exercises were begun on postoperative day 1 in a removable POP splint. Patients were followed at 6 wks., 12 wks., 24 wks. and 52 wks. and then 6 monthly. At each followup, a thorough clinical evaluation and standard radiographic assessment was carried out. Patients were kept nonweightbearing for initial 6 weeks and gradually mobilised from touchdown weightbearing with support to full weightbearing over the next 6-12 wks. Overall assessment including measurement of Bohler's angle, range of motion at ankle and subtalar joint, ability to wear normal shoes, return to original job and Maryland foot scoring was done at a mean 16 months' followup (range 12-24 months).

\section{RESULTS}

After a mean followup of 16 months, the mean Maryland foot score was 82 points (maximum 100 points). Bohler's angle measured a mean 28 degrees (range 20-45 degrees). More than $80 \%$ of patients were able to wear normal shoes and return to their original job. Good to excellent range of motion at ankle and subtalar joints was obtained in most cases. Local wound infection occurred in 3 patients $(8.3 \%)$. All three were successfully treated with local debridement, regular dressings and IV antibiotics. A total of 12 patients required removal of hardware either due to infection or due to palpable or painful screw heads. Three patients required subtalar arthrodesis due to persistent ankle pain but only after fracture healing and hardware removal.

\section{CONCLUSION}

We consider that closed reduction and percutaneous fixation of intra-articular calcaneal fractures with cancellous screws is an excellent treatment option producing good clinical and functional results with minimal complications.

\section{KEYWORDS}

Calcaneal Fractures, Percutaneous Fixation.

HOW TO CITE THIS ARTICLE: Nama KG, Meena RK, Sharma SB. Management of intra-articular calcaneal fractures with reduction and percutaneous fixation. J. Evolution Med. Dent. Sci. 2017;6(58):4303-4307, DOI: 10.14260/Jemds/2017/930

\section{BACKGROUND}

The calcaneum is the most frequently fractured bone in the foot accounting for $1-2 \%$ of all fractures. Nearly $3 / 4^{\text {th }}$ of calcaneal fractures are intra-articular. The complex pattern seen in calcaneal fractures along with often compromised soft tissues presents challenges to the treating trauma surgeon. Conflicting opinions on the management of these fractures further add to the dilemma.

Traditionally, nonoperative management was advocated by most surgeons and even today clinical evidence

Financial or Other, Competing Interest: None.

Submission 31-05-2017, Peer Review 08-07-2017,

Acceptance 14-07-2017, Published 20-07-2017.

Corresponding Author:

Dr. Kishan Gopal Nama

B-17, Civil Line,

Opposite MBS Hospital, Kota.

E-mail: drkgnama1808@gmail.com

DOI: $10.14260 /$ jemds $/ 2017 / 930$

\section{(c)}

supporting operative treatment is limited. However, evidence is continuously growing in favour of internal fixation with minimally invasive percutaneous techniques in selected patients.

Several techniques have been described in the past for closed reduction of calcaneal fractures. The Essex-Lopresti manoeuvre ${ }^{1}$ with a few minor modifications is successful in most cases. Forgon ${ }^{2}(1983)$ described closed reduction of calcaneal fractures using distraction screws placed in cuboid and talus and manipulation of fracture fragments using a lateral pin and Bohler's clamp.

The aim of this study is to report techniques and results of closed reduction and percutaneous fixation of intraarticular calcaneal fractures.

\section{MATERIALS AND METHODS}

Between July 2011 to August 2013, 40 intra-articular calcaneal fractures in 36 patients were treated by closed reduction and percutaneous fixation. It was a case series 
conducted after the clearance from ethical committee. All the cases were studied in detail with regards to age, sex and occupation of patients, mode of injury, the mechanism of injury, fracture pattern, medical comorbidities, other associated bony injuries, duration of reporting after injury and time interval between injury and treatment. Superficial skin condition was also noted.

Patients with extra-articular calcaneal fractures, compound fractures and those with complex ankle and foot injuries as well as those with multiple long bone fractures were excluded from the study.

All patients were evaluated preoperatively with standard radiographs, including AP and lateral view of foot and axial view of calcaneum. Radiographs of opposite healthy limb were also taken for comparison. A preoperative CT scan was also routinely acquired for all patients and fractures were classified according to Essex-Lopresti Classification and Sanders classification.

Postoperative standard radiographs were made to assess adequacy of reduction, restoration of Bohler's angle and calcaneal width.

All patients were operated as soon as possible after injury.

Routine antibiotic prophylaxis was used in all cases.

All patients were operated under spinal anaesthesia in lateral decubitus position on a radiolucent operation table.

The well leg was kept down and anterior relative to the affected leg. Firm bumps placed under the affected foot were used to obtain a true lateral position of the foot.

The C-arm was positioned at the foot end of operating table. Varying the tilt and rotation of C-arm towards the foot end and underneath the table allows true lateral view, oblique lateral view of subtalar joint and Harris axial view with minimal manipulation of foot.

Reduction of fracture was carried out by Essex-Lopresti manoeuvre with minor modifications.

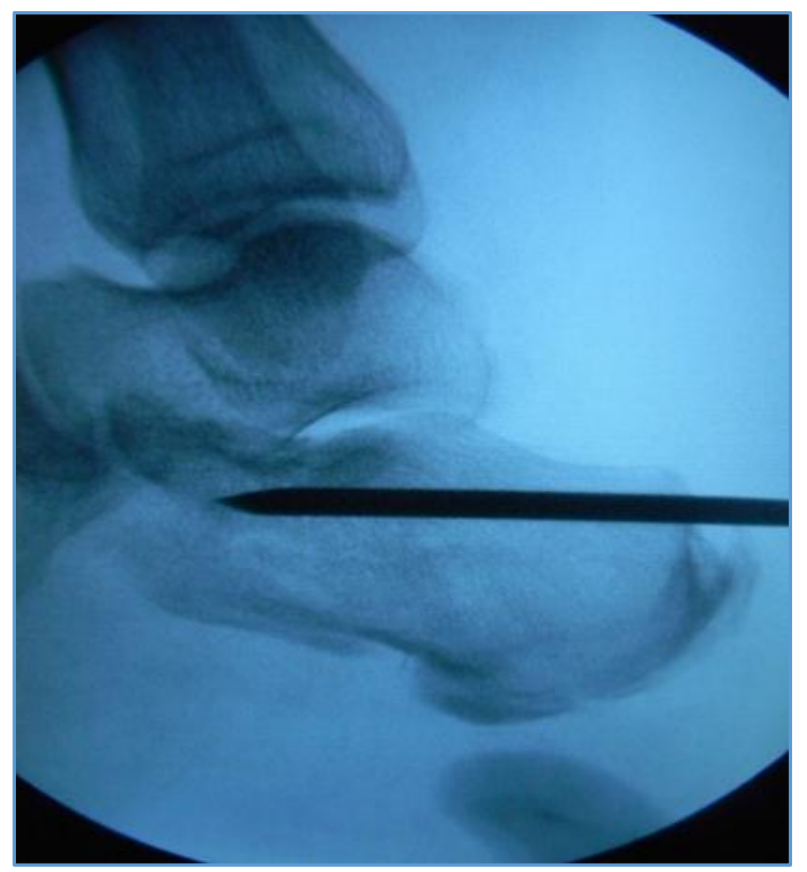

Figure 1.1. Essex-Lopresti Manoeuvre
One of these modifications was the placement of a threaded pin in the tuberosity from lateral to medial side to correct varus and to achieve length. Once the tuberosity is positioned correctly the facet fragments fit well beneath the talar articular surface and intact sustentaculum medially. A Steinman pin/small periosteal elevator inserted through a stab incision on lateral surface was occasionally used to unlock and push up any depressed parts of subtalar portion of calcaneum.

Once the fracture is reduced on all three standard C arm views, it was provisionally fixed with $1.6 \mathrm{~mm} \mathrm{~K}$ wires. Partially threaded $4.0 \mathrm{~mm}$ and $6.5 \mathrm{~mm}$ cannulated cancellous screws were used for definitive fixation.

For most fractures, the first screw was directed from the lateral side, through the facet fragment and into the sustentaculum tali. The screw path is assisted by the true and oblique lateral views and the Harris view confirms exact length of the screw required.

The tuberosity was next fixed with the screw starting posterolaterally and directed anteromedially, the exact length being determined by lateral view. Whenever required, additional screws were placed either extending from posteromedial to anterolateral part of calcaneum or from the tongue fragment into the posteroinferior part of tuberosity. All screws were firmly placed against the bone to minimise screw head prominence and length and positions confirmed on all 3 standard $C$ arm views. The stab incisions were closed and sterile dressings applied.

Postoperatively limb was supported in a removable below knee POP splint and elevated for 48-72 hrs. Passive and active toe, ankle and subtalar range of motion exercises were encouraged from postoperative day 1 and gradually increased in duration over the next few days as tolerated by the patient. Sutures were routinely removed at 2 weeks.

A routine followup was planned for all patients at 6 wks., 12 wks., 24 wks., 52 wks. and then every 6 months. At each followup, radiographs were taken to check fracture alignment, Bohler's angle, calcaneal width, length and height. Also functional evaluation was done using Maryland foot score. Patients were kept non-weightbearing for initial 6 weeks and then gradually mobilised from touchdown weightbearing with support to full weightbearing. Active and passive ROM exercises were started after 3 months postoperatively.

\section{RESULTS}

All the patients were in 20-50 years age group (mean 32.6 years) with male to female ratio of $8: 1$. Bilateral fractures were noted in 4 patients. The most common mode of injury in our series was fall from height (78\%) followed by road traffic accidents $22 \%$ (7:2). Associated fractures included vertebral fractures in 5 patients (15\%) and fractures of pelvis in 2 patients. In our series, 28 fractures were Essex-Lopresti joint depression type, 8 were tongue type and 4 were severely comminuted fractures. According to Sanders classification, 2 were Sanders grade I, 22 were grade II, 12 were grade III and 4 were Sanders grade IV. The mean duration from the time of injury and surgical procedure was 2.7 days (range 1-6 days).

After a mean followup of 16 months (range 12-24 months), the mean Maryland foot score was 82 (maximum 
100 points). The average range of ankle motion was 45 degrees (range 30-50 degrees). In unilateral cases this represented a mean $80 \%$ of range of motion at the opposite healthy foot. The average range of motion at subtalar joint was 20 degrees (range 5-30 degrees). In unilateral cases this represented a mean $70 \%$ of range of motion as compared to the opposite healthy foot.

The Bohler's angle as measured on lateral radiographs changed from a mean 5 degrees preoperatively (range -30 to +10 degree) to a mean 36 degrees postoperatively (range 20 45 degrees). At mean followup of 16 months, the Bohler's angle averaged 28 degrees (range 20-35 degrees). More than $80 \%$ of patients returned to their original job within $6-8$ months. Six patients required custom made shoes and rest of the 30 patients were able to wear normal shoes.

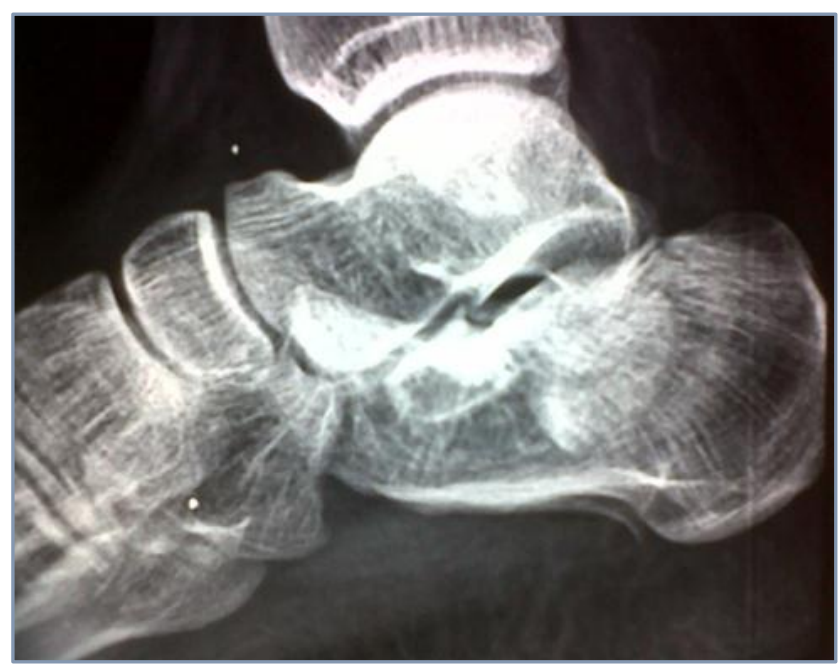

Figure 1.2. Pre-op X-ray

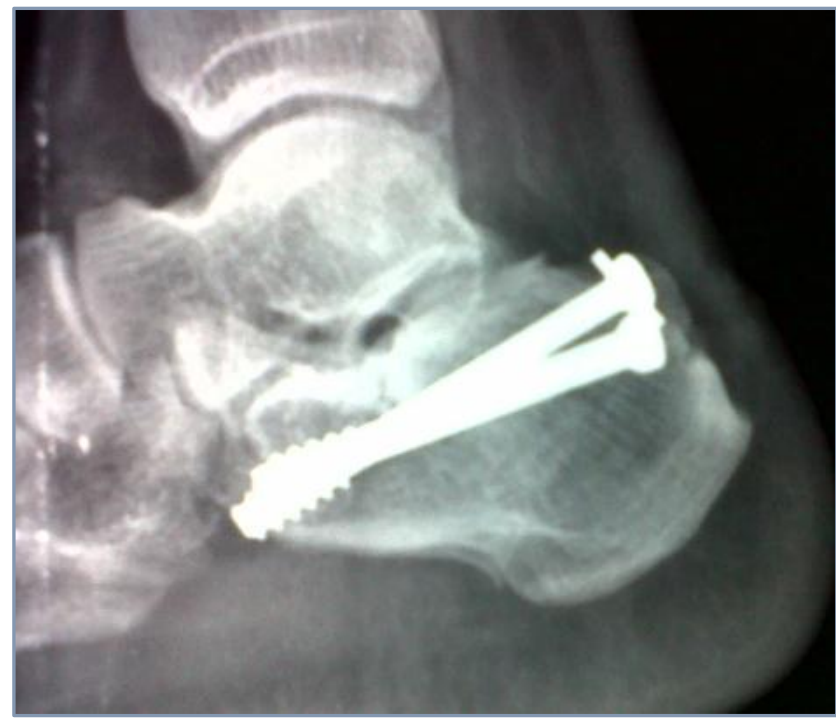

Figure 1.3. One-year Followup $X$-ray (Lateral View)

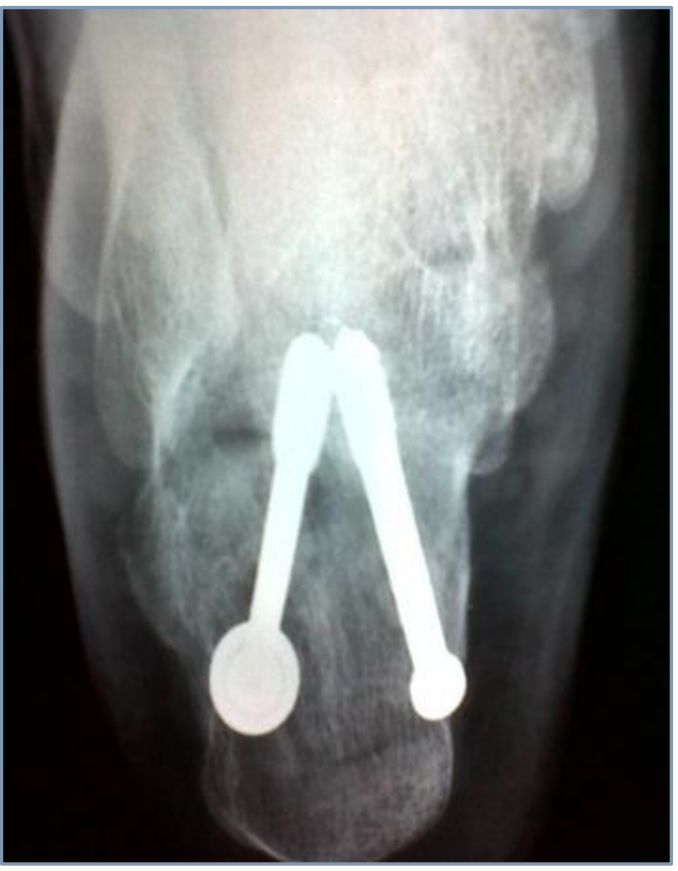

Figure 1.3. One-year Followup X-ray, Axial View

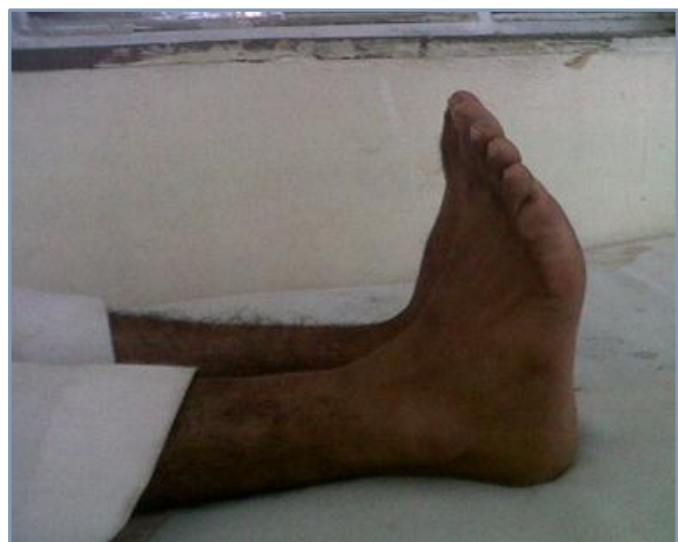

Figure 1.4. One-year Followup: Good Range of Dorsiflexion

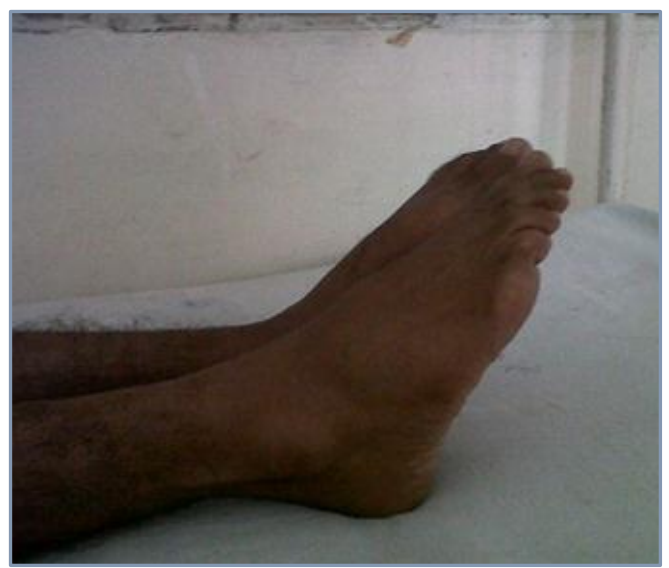

Figure 1.5. One-year Followup: Good Range of Plantarflexion 


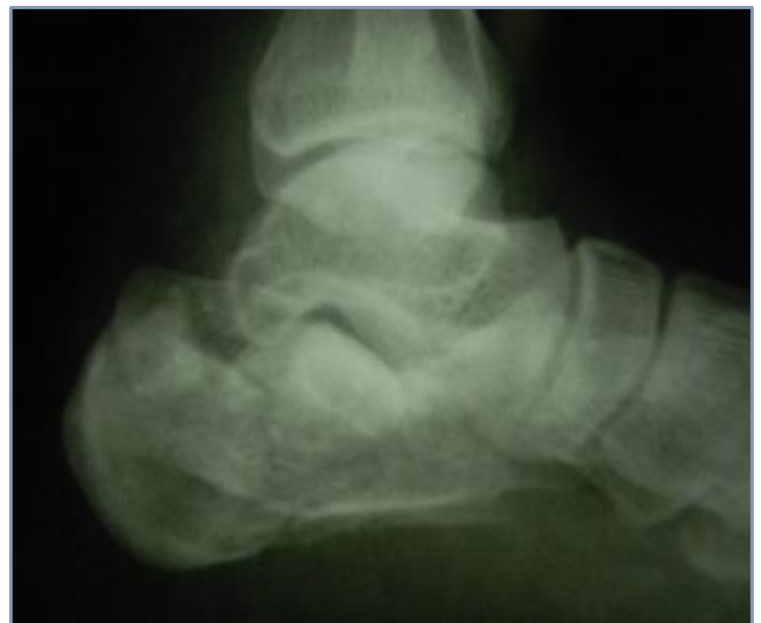

Figure 2.1. Pre-op X-ray of a Comminuted Fracture in a 48-year-old Male.

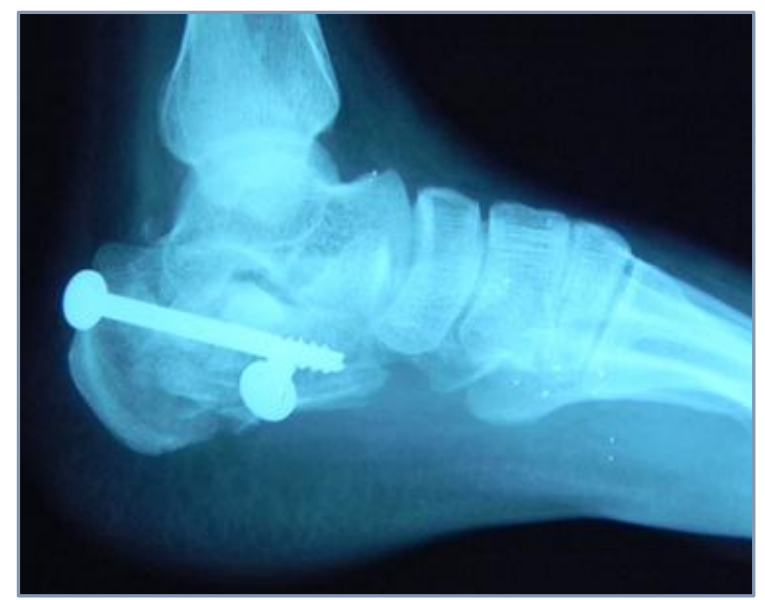

Figure 2.2. One-year Followup X-ray showing Fracture Healing in a Fair Alignment

Local wound infection developed in 3 cases (8.3\%). All three were successfully treated with local debridement, regular dressings and oral antibiotics. A total of 12 patients required screw removal either due to local infection or due to palpable/painful screw heads. Three patients required subtalar arthrodesis due to persistent pain but only after fracture healing and hardware removal.

\section{DISCUSSION}

Treatment of displaced intra-articular calcaneal fractures is a matter of debate and remains controversial. In the past, calcaneal fractures were treated non-operatively but often with unsatisfactory results. Even today, clinical evidence in support of operative treatment is limited, still open reduction and internal fixation is the treatment of choice for displaced intra-articular fractures at most of the centres.

Complication associated with ORIF has raised concerns among most trauma surgeons all over the world. Starr AJ et $\mathrm{al}^{3}$ analysed 190 calcaneal fractures treated operatively and reported a complication rate of $25 \%$. Zwipp et $\mathrm{al}^{4}$ analysed 123 cases of calcaneal fractures and reported superficial wound edge necrosis in $8.3 \%$ of these cases. Buckley et $\mathrm{al}^{5}$ showed a superficial wound complication rate of $17 \%$ and a deep infection rate of $5 \%$ in the operative group treated with open reduction and plate fixation. Sanders et al ${ }^{6}$ in a series of 120 surgically treated patients reported significant wound complications in 16 patients.

To minimise wound complications, techniques were developed employing close reduction and percutaneous fixation of these fractures. Tornetta et $\mathrm{al}^{7}$ reported good to excellent results in $87 \%$ of their cases following percutaneous reduction by Essex-Lopresti manoeuvre and screw fixation. Walde et $\mathrm{al}^{8}$ and Stulik et $\mathrm{al}^{9}$ reported good results with closed reduction/minimally invasive open reduction and $\mathrm{K}$ wire fixation; with a superficial wound infection rate of 6-7\%. Forgon et $\mathrm{al}^{2}$ used distraction screws placed in cuboid and talus to achieve closed reduction; they reported $85 \%$ good to excellent results in their study of 265 intra-articular calcaneal fractures.

Tomeson et al ${ }^{10}$ used distraction screws placed in distal tibia and calcaneal tuberosity followed by insertion of a transcalcaneal rod from plantar direction to manipulate the displaced fragments. In their study of 39 intra-articular calcaneal fractures, the mean AOFAS and Maryland foot score were 84 and 86 points (Maximum 100) respectively, they reported a wound complication rate of $13 \%$.

In our present study of 40 calcaneal fractures in 36 patients, the mean Maryland foot score was 82 points with a wound complication rate of $8.3 \%$ which is comparable to study by Tomeson et al. ${ }^{10}$ All of the infections in our cases were local screw tract infections and were successfully treated by local debridement and oral antibiotics. Screw removal was eventually required in all 3 patients. Another 9 patients $(25 \%)$ required removal of screws due to palpable/painful screw heads. We believe that in future, development of cancellous screws with low profile heads can minimise this complication.

Near anatomical reductions (Step-off of $2 \mathrm{~mm}$ or less) were obtained in most of our cases as evident by adequate Bohler's angle, joint congruity and restoration of calcaneal length, width and height on post-operative radiographs. The mean Bohler's angle at average 16 months followup in our study was 28 degrees as compared to 20.1 degrees at average 66 months in the study by Tomeson et al. ${ }^{10}$

Three patients had persistent pain even after fracture healing and hardware removal and were satisfactorily treated with subtalar arthrodesis at a mean 13 months. These patients had severely comminuted fracture (Sanders grade IV) and only a fair reduction could be obtained with our technique. Subtalar arthrodesis was technically easier in all three patients when compared to similar procedure in patients treated conservatively for calcaneal fracture. We agree with studies of Craig et $\mathrm{al}^{11}$ and Buckley et $\mathrm{al}^{5}$ that, if required, subtalar fusion is easier in operatively treated calcaneal fractures as a fair calcaneal shape and alignment is already restored.

$82 \%$ of our patients were able to wear normal shoes which is comparable to results of study by Schepers et $\mathrm{al}^{12}$ and Tomeson et $\mathrm{al}^{10}$ using a comparable surgical technique.

\section{CONCLUSION}

Treatment of intra-articular calcaneal fractures with closed reduction and percutaneous fixation is an excellent treatment option producing good clinical and functional results with minimal complications. 


\section{REFERENCES}

[1] Essex-Lopresti P. The mechanism, reduction technique and results in fractures of the os calcis. Br J Surg 1952;39(157):395-419.

[2] Forgon M. Closed reduction and percutaneous osteosynthesis: technique and results in 265 calcaneal fractures. In: Tscherne $\mathrm{H}$, Schatzker J. eds. Major fractures of the pilon, the talus and the calcaneus: current concepts of treatment. Berlin: Springer-Verlag 1993:207-13.

[3] Folk JW, Starr AJ, Early JS. Early wound complications of operative treatment of calcaneus fractures: analysis of 190 fractures. J Orthop Trauma 1999;13(5):369-72.

[4] Zwipp $H$, Tscherne $H$, Thermann $H$, et al. Osteosynthesis of displaced intraarticular fractures of the calcaneus. Results in 123 cases. Clin Orthop Relat Res 1993;290:76-86.

[5] Buckley R, Tough S, McCormack R, et al. Operative compared with nonoperative treatment of displaced intra-articular calcaneal fractures: a prospective, randomized, controlled multicenter trial. J Bone Joint Surg Am 2002;84-A(10):1733-44.

[6] Sanders R, Fortin P, DiPasquale T, et al. Operative treatment in 120 displaced intraarticular calcaneal fractures. Results using a prognostic computed tomography scan classification. Clin Orthop Relat Res 1993;290:87-95.
[7] Tornetta P. The Essex-Lopresti reduction for calcaneal fractures revisited. J Orthop Trauma 1998;12(7):46973.

[8] Walde TA, Sauer B, Degreif J, et al. Closed reduction and percutaneous Kirschner wire fixation for the treatment of dislocated calcaneal fractures: surgical technique, complications, clinical and radiological results after 2-10 years. Arch Orthop Trauma Surg 2008;128(6):585-91.

[9] Stulik J, Stehlik J, Rysavy M, et al. Minimally-invasive treatment of intra-articular fractures of the calcaneum. J Bone Joint Surg Br 2006;88(12):1634-41.

[10] Tomeson T, Biert J, Frolke JP. Treatment of displaced intra-articular calcaneal fractures with closed reduction and percutaneous screw fixation. J Bone Joint Surg Am 2011;92(10):920-8.

[11] Craig SR, Clare MP, Sanders RW. Subtalar fusion after displaced intra-articular calcaneal fractures: does initial operative treatment matter? J Bone Joint Surg Am 2009;91(3):541-6.

[12] Schepers T, Schipper IB, Vogels LM, et al. Percutaneous treatment of displaced intra-articular calcaneal fractures. J Orthop Sci 2007;12(1):22-7. 